\title{
Karyological Characterization of Four Marine Fish Species, Genera Trachinotus and Selene (Perciformes: Carangidae), from the Southeast Brazilian Coast
}

\author{
Mirian Molnar Rodrigues, Sabrina Baroni and \\ Lurdes Foresti de Almeida-Toledo*
}

Departamento de Genética e Biologia Evolutiva, Instituto de Biociências, Universidade de São Paulo, Caixa Postal 11.461-05422-970, São Paulo, Brazil

Received December 6, 2006; accepted January 31, 2007

\begin{abstract}
Summary Specimens of 4 marine fish species 3 from genus Trachinotus, T. carolinus, T. falcatus, T. goodei, and 1 from genus Selene, S. vomer belonging to the family Carangidae (Perciformes) were analyzed. All the specimens analyzed inhabit the South/Southeast coast of Brazil, and were sampled from the locality São Sebastião, SP. The 4 species presented $2 n=48$ chromosomes, being the chromosome formula for Selene vomer $46 \mathrm{~A}+2 \mathrm{ST}$, T. carolinus $8 \mathrm{MSM}+40 \mathrm{~A}$, T. falcatus $38 \mathrm{~A}+10 \mathrm{MSM}$ and T. goodei $4 \mathrm{MSM}+44 \mathrm{~A}$ chromosomes. The 4 species presented 1 pair of NORs. Small blocks of heterochromatin were found in these 4 species. The karyotypic characteristics of these species were discussed in comparison with other species and populations of Perciformes already analysed.
\end{abstract}

Key words Perciformes, Marine fish, Karyotype,Trachinotus, Selene.

The order Perciformes is the most diversified of all fish orders and the largest order of vertebrates, comprehending 20 suborders, 160 families, 1539 genera and about 10033 species (Nelson 2006), being marine species $75 \%$ of the components of this fish order. The family Carangidae is one of the largest families of Perciformes, with approximately 32 genera, including Trachinotus and Selene, and 140 species (Nelson 2006). Genus Trachinotus comprehends about 20 species, distributed in the tropical and subtropical areas of all oceans, being the species T. carolinus, T. falcatus and T. goodei, the more widely distributed in these areas (Cunha 1981). The genus Selene has representatives in the tropical waters of the Atlantic and Pacific oceans, as S. vomer and S. setapinnis, which are also present in the Brazilian coast (Netto 1997).

The cytogenetic analysis of fish species is well advanced for the freshwater fish that inhabit Brazilian rivers, and a growing number of species is being analyzed, so that an expressive amount of information is currently available for this group. This fact results in a great amount of data about the evolutionary relationship of species and genera of freshwater species. In some cases, the cytogenetic information associated with molecular markers was used in the description of new species (Albert et al. 1999). When compared with the amount of data available for freshwater fish species from the Neotropical region, the cytogenetic information about marine fishes from the Brazilian coast is still incipient.

In a preliminary analysis of Trachinotus carried out by Zeinad and Almeida-Toledo (1994) the chromosome number and morphology for T. carolinus and T. falcatus were established. Pauls et al. (1998) and Netto et al. (1998) described respectively the karyotype of T. goodei and the chromosome number and formula of Selene volmer. All these analysis were performed using conventional Giemsa staining. However, no data about the C-banding pattern of heterochromatin or nucleolus or-

*Corresponding author, e-mail: 1ftoledo@usp.br. 
ganizer region (NOR) location are available for these species so far.

Here we present the karyotypes of 3 species of Trachinotus, T. carolinus. T. falcatus and T. goodei and of 1 species of genus Selene, S. volmer, sampled from the coastal region of the State of São Paulo, Brazil, including NOR location and, for the first time, the C-banding pattern of these 4 species.

\section{Material and methods}

Specimens of 4 marine fish species 3 from genus Trachinotus, T. carolinus, T. falcatus, T. goodei, and 1 from genus Selene, $S$. vomer belonging to the family Carangidae (Perciformes) were analyzed. All the specimens analyzed inhabit the South/Southeast coast of Brazil, and were sampled from the locality São Sebastião, SP.

Mitotic chromosome preparations were obtained from kidney cells using the air-drying technique according to Foresti et al. (1981). Chromosome morphology was determined on the basis of arm ratio, as proposed by Levan et al. (1964) and the chromosomes were classified as metacentrics (M), submetacentrics (SM), subtelocentrics (ST) and acrocentrics (A). The NF (chromosome arm number) was determined, considering metacentric and submetacentric chromosomes as having 2 arms and acrocentric chromosomes, 1 arm. C-banding was performed according to Sumner (1972) and the NOR position was detected after silver staining according to Howell and Black (1980).

\section{Results}

\section{Selene vomer}

This species presents $2 n=48$ chromosomes and NF=50, being 46 acrocentrics, and 2 subtelocentric chromosomes (Fig. 1a). The NOR is located interstitially on the short arm of the subtelocentric pair (pair $\mathrm{N}^{\circ}$ 1) (Fig. 1a, inset). Small heterochromatic blocks are located in the pericentromeric region of the NOR-bearing chromosome pair (Fig. 1b) and in the pericentromeric region of the acrocentric chromosomes.

\section{Trachinotus carolinus}

This species presents $2 n=48$ chromosomes $(\mathrm{NF}=56)$, being 8 metacentric/submetacentric chromosomes and 40 acrocentrics (Fig. 2a). The NORs are located on the short arm of 1 pair of acrocentrics (Fig. 2a, inset). Small heterochromatic blocks are present at the pericentromeric region of chromosomes and associated to the NORs (Fig. 2b).

\section{Trachinotus falcatus}

This species presents $2 n=48$ chromosomes $(\mathrm{NF}=58)$, being 38 acrocentrics and 10 metacentric/submetacentric chromosomes (Fig. 3a). The NOR is located on the short arm of an acrocentric chromosome pair (Fig. 3a, inset). Small heterochromatic blocks are located on the pericentromeric region of all chromosomes and are also associated with the NORs (Fig. 3b).

\section{Trachinotus goodei}

This species presents $2 n=48$ chromosomes $(\mathrm{NF}=52)$, being 4 metacentric-submetacentric chromosomes and 44 acrocentric chromosomes (Fig. 4a). The NOR is located on the short arm of an acrocentric chromosome pair (Fig. 4a, inset). Small heterochromatic blocks are present in the pericentromeric region of all chromosomes and are also found associated with the NORs (Fig. 4b). The heterochromatic block associated with NORs present different sizes, probable due to differential ribosomal gene duplication. 


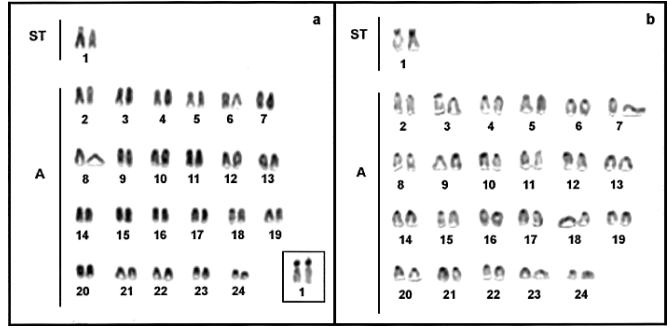

Fig. 1. Selene vomer. a) Giemsa stained karyotype; Inset: silver stained NOR. b) C-banding pattern.

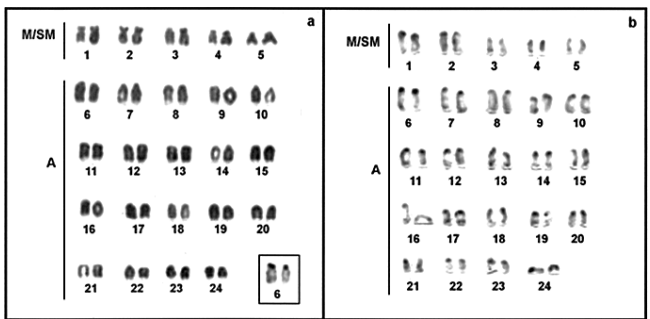

Fig. 3. Trachinotus falcatus. a) Giemsa stained karyotype; Inset: silver stained NOR. b) C-banding pattern.

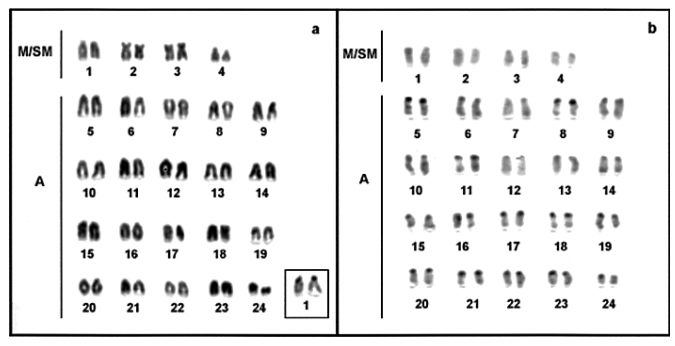

Fig. 2. Trachinotus carolinus. a) Giemsa stained karyotype; Inset: silver stained NOR. b) C-banding pattern.

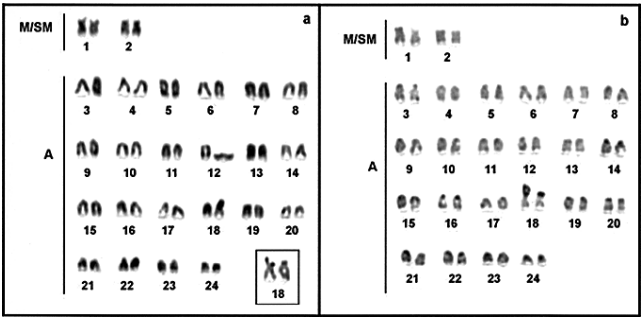

Fig. 4. Trachinotus goodei. a) Giemsa stained karyotype; Inset: silver stained NOR. b) C-banding pattern.

\section{Discussion}

The present work is a contribution to the karyotypical data on marine fish species, a group that has been relatively less studied than freshwater species. Considering the order Perciformes, karyotipes of approximately 600 species have been analyzed so far, which correspond to $7 \%$ of the number of described species for this order (Affonso 2000); for the Neotropical species chromosome data are available for about only 100 species (Oliveira 2004).

The chromosome numbers here described for T. falcatus and T. carolinus corroborate the karyotypic formulae of previous data obtained by Zeinad and Almeida-Toledo (1994). In relation to T. goodei, our data diverge from those obtained by Netto et al. (1998) that proposes the karyotypic constitution of $2 \mathrm{M}+46 \mathrm{~A}$ for this species, while our present data indicate $4 \mathrm{M} / \mathrm{SM}+44 \mathrm{~A}$. This disagreement could be possibly explained by the small size of the chromosomes of this species, a problem that was partially circumvented by the difference in the methodology used in our chromosome preparation that resulted in a better morphological characterization of these very small chromosomes.

A similar problem occurs in relation to $S$. vomer, in that our results diverge of those obtained by Netto (1997) in relation to the chromosome formula $2 \mathrm{MSM}+46 \mathrm{~A}$ proposed by this author: the chromosome formula and Fundamental Number found in the present study for this species are $2 \mathrm{ST}+46 \mathrm{~A}$ and $\mathrm{NF}=50$. A single NOR pair was detected in the short arm of the subtelocentric chromosome pair in S. vomer in the present analysis, while Netto (1997) described the occurrence of four NORs that were detected both in a submetacentric and one acrocentric chromosome pair.

The presence of a single pair of NOR is considered the basic situation for the majority of the vertebrates. In Perciformes, the presence of a single NOR pair in interstitial position seems to be the most frequent situation (Affonso 2000). For the genus Trachinotus here studied, however, the NOR is located on the short arm of an acrocentric chromosome pair. 
Approximately $60 \%$ of the perciform species thus far studied show a karyotype characterized by 48 uniarmed chromosomes (Galetti Jr. et al. 2000). The 3 Trachinotus species here analyzed also presented $2 n=48$ chromosomes and the number of biarmed chromosomes is larger than that from Selene vomer that presents also $2 n=48$ chromosomes and only one pair of biarmed chromosomes. This fact may indicate a tendency for bi-armed chromosomes in Trachinotus, but more data from a larger number of specimens are necessary to test this assumption.

The pattern of heterochromatin distribution after C-banding can be related to the conservative characteristics of Perciformes. Most of species, as the ones in this study, present very few heterochromatin, in small heterochromatic blocks restricted to pericentromeric regions or associated interstitially with NORs (Brum 1996).

Among the 71 species of Perciformes analyzed in the Neotropical region, the chromosome number varies from $2 n=24$ found in Mugil curema, that presents a large number of biarmed chromosomes, to $2 n=50$ in Priacanthus arenatus, with an expressive predominance of $2 n=48$ in the other species already analysed. The NF varies from $\mathrm{NF}=46$, found in species as Micropogonias furnieri with $(2 n=46 ; \mathrm{NF}=46)$, to $\mathrm{NF}=92$, found in Stegastes sanctipauli $(2 n=48 ; \mathrm{NF}=92)$ (Oliveira 2004). Karyotypes with $2 n=48$ and $\mathrm{NF}=48$ are considered primitive and this plesiomorphic condition appears to be specially conserved in marine species (Galetti Jr. et al. 2000). The occurrence of a $2 n=48$ diploid number and the characteristic gradual size variation of the chromosomes in the four species here analyzed, as well as the small size of the chromosomes reinforces the conservation of the character $2 n=48$ in the chromosomal evolution in this group of marine fish. On the other hand, the different chromosome morphology detected in all the 4 species shows that a number of chromosome rearrangements have occurred in the evolutionary story of these fish and the occurrence of biarmed chromosomes is probably due to pericentric inversion events, changing the NF but maintaining the chromosome number $2 n=48$ as a predominant number for the group.

This tendency probably indicates that, in spite of the conservation in chromosome number, many structural rearrangements have occurred in the evolutionary story of these fishes and this may be tested when more resolutive cytogenetic techniques are used in the karyotypic analysis of these species.

\section{Acknowledgements}

Supported by Fundação de Amparo à Pesquisa do Estado de São Paulo (FAPESP) and Conselho Nacional do Desenvolvimento Científico e Tecnológico (CNPq). We thank C. E. Lopes by technical assistance and the Instituto de Biologia Marinha, USP, for facilities in the sample collection.

\section{References}

Albert, J. S., Fernandes-Matioli, F. M. C.and Almeida-Toledo, L. F. 1999. New species of Gymnotus (Gymnotiformes, Teleostei) from Southeastern Brazil: Toward the Deconstruction of Gymnotus carapo. Copeia, 1999: 410-421.

Affonso, P. R. A. M. 2000. Caracterização Citogenética de Peixes de Recifes de Corais da Família Pomacanthidae (Perciformes). Dissertação de Mestrado. Centro de Ciências Biológicas e da Saúde. Universidade Federal de São Carlos.

Brum, M. J. I. 1996. Cytogenetic Studies of Brazilian Marine Fish. Revista Brasileira de Genética 19: 421-427.

Cunha, L. P. R. 1981. Importância da Zona de Arrebentação de Praias Para o Desenvolvimento dos Juvenis Trachinotus (PISCES, CARANGIDAE): Aspectos da Bioecologia e Distribuição Geográfica do Gênero, Com Ênfase às Espécies que Ocorrem no Litoral Sul/Sudeste do Brasil e no Atlântico Ocidental. PhD Thesis . Instituto de Biociências. Universidade de São Paulo.

Foresti, F., Almeida-Toledo, L. F. and Toledo-Filho, S. A. 1981. Polymorphic nature of nucleolus organizer regions in fishes. Cytogenet. Cell Genet 31: 137-144.

Galetti-Jr., P. M., Aguilar, C. T. and Molina, W. 2000. An Overview of Marine Fish Cytogenetics. Hydrobiologia 420: $55-62$.

Howell, W. M. and Black, D. A. 1980. Controlled silver-staining of nucleolus organizer regions with a protective colloidal 
developer: a 1-step method. Experientia 36: 1014-1015.

Levan, A., Fredga, K. and Sandberg, A. A. 1964. Nomenclature for centromeric position on chromosomes. Hereditas 52: 201-220.

Nelson, J. S. 2006. Fishes of the world. Fourth Edition., John Willey \& Sons, Inc. New York.

Netto, M. R. C. B. 1997. Caracterização citogenética de cinco espécies de peixes marinhos (Família Carangidae) economicamente importantes com potencial para a aqüicultura. Monography. Faculdade de Veterinária. Universidade Federal Fluminense.

-, Affonso, P. R. A. M., Oliveira, A. S. S., Muniz, A. and Pauls, E. 1998. Estudos citogenéticos em peixes marinhos: Trachinotus goodei (Linnaeus, 1758) (Perciformes, Carangidae). VII Simpósio de Citogenética Evolutiva e Aplicada de Peixes Neotropicais. Londrina, PR, Book of Abstracts C.13.

Oliveira, C. 2004. Lista de Peixes Neotropicais. Data base. Access dec/2004.

Sumner, A. T., 1972. A simple technique for demonstrating centromeric heterochromatin. Exp. Cell Res. 75: 304-306.

Zeinad, A. K. and Almeida-Toledo, L. F. 1994. O Cariótipo de Trachinotus carolinus e Trachinotus falcatus (Pisces, Carangidae). V Simpósio de Citogenética Evolutiva e Aplicada de Peixes Neotropicais. Botucatu, SP. Book of Abstracts. 